\title{
Produção e composição do leite, metabólitos sangüíneos e concentração hormonal de cabras lactantes da raça Toggenburg tratadas com somatotropina bovina recombinante ${ }^{1}$
}

\section{Elenice Andrade Moraes e Amorim ${ }^{2}$, Ciro Alexandre Alves Torres ${ }^{3}$, José Henrique Bruschi ${ }^{4}$, Jefferson Ferreira da Fonseca ${ }^{5}$, José Domingos Guimarães ${ }^{6}$, Paulo Roberto Cecon ${ }^{7}$, Giovanni Ribeiro de Carvalho ${ }^{3}$}

\author{
${ }^{1}$ Parte da dissertação de Mestrado da primeira autora. Pesquisa financiada pela FAPEMIG. \\ 2 Pós-Graduação - Departamento de Zootecnia da UFV. \\ ${ }^{3}$ Departamento de Zootecnia da UFV - Viçosa, MG. \\ ${ }^{4}$ Embrapa Gado de Leite - Juiz de Fora, MG. \\ ${ }^{5}$ Embrapa Caprinos - Sobral, CE. \\ ${ }^{6}$ Departamento de Veterinária da UFV - Viçosa, MG \\ ${ }^{7}$ Departamento de Informática da UFV - Viçosa, MG
}

RESUMO - Estudou-se a influência da aplicação de somatotropina bovina recombinante sobre a produção e composição do leite, os metabólicos sangüíneos e a concentração hormonal em cabras no terço médio da lactação. Foram utilizadas 24 cabras da raça Toggenburg, divididas em dois tratamentos: T1 (n=12): aplicação de $250 \mathrm{mg}$ de r-bST a cada 14 dias, em um total de quatro aplicações; e T2 (n=12): aplicação de solução salina (controle). O tratamento com r-bST não aumentou a produção de leite e não influenciou os teores de gordura, proteína e extrato seco. A porcentagem de lactose no leite foi maior (4,47 \pm 0,2 para T1 versus 4,34 $\pm 0,2 \%$ para T2) e a contagem de células somáticas menor nos animais tratados em relação aos controle $(681,1 \pm 689,9$ para T1 versus $1.001,84 \pm 610,9$ [x10 células $/ \mathrm{mL}]$ para T2). A administração de r-bST aumentou as concentrações séricas de ácidos graxos não-esterificados de T2 $(309,67 \pm 169,62$ x 247,34 $\pm 126,38 \mathrm{mEq} / \mathrm{L}$, para T1 e T2, respectivamente) e reduziu as concentrações de uréia $(86,84 \pm 33,81 \times 121,16 \pm 42,57 \mathrm{mg} / \mathrm{dL}$, para T1 e T2 respectivamente) A r-bST reduziu as concentrações de colesterol total e HDL $(82,46 \pm 19,25$ x 89,29 $\pm 23,66 \mathrm{mg} / \mathrm{dL}$ e $155,95 \pm 19,67 \times 177,67$ $\pm 32,79 \mathrm{mg} / \mathrm{dL}$, para T1 e T2 respectivamente), enquanto as concentrações de albumina, glicose, proteínas totais, $\beta$-hidroxibutirato e tiroxina não foram influenciadas pela r-bST, que também não influenciou o peso e o escore corporal dos animais. A r-bST aumentou os teores de lactose, reduziu a contagem de células somáticas e promoveu alterações nos metabólicos sangüíneos e no leite de cabras lactantes.

Palavras-chave: constituintes do leite, cabras, lactação, metabólitos, tiroxina

\section{Milk yield and composition, blood metabolites and hormonal profile of lactating Toggenburg goats treated with recombinant bovine somatotropin}

ABSTRACT - The objective of this trial was to study the effects of recombinant bovine somatotropin on milk yield and composition, blood metabolites and hormonal profile in lactating goats. Twenty-four Toggenburg goats were assigned to one of two treatments as follows: T1 $(n=12)$ received injection of $250 \mathrm{mg}$ of $\mathrm{r}$-bST, every 14 days (four injections), and T2 $(\mathrm{n}=12)$ received injections of saline solution (control). No significant differences on milk yield and composition (fat, protein, and dry extract) were observed comparing r-bST-treated goats with non-treated animals However, milk lactose content was higher $(P<0.05)$ on goats that received r-bST $(4.47 \pm 0.2)$ than on those treated with saline solution $(4.34 \pm 0.2 \%)$ while somatic cells count was lower on $\mathrm{T} 1(681.1 \pm 689.9)$ than on $\mathrm{T} 2[(1,001.84$ $\pm 610.9(\mathrm{x} 103 \mathrm{cells} / \mathrm{mL})]$. Injection $\mathrm{r}$-bST increased the concentration of non-esterified fatty acid compared to the saline-treated animals $(309.67 \pm 169.62$ vs. $247.34 \pm 126.38 \mathrm{mEq} / \mathrm{L})$ but the opposite was observed for urea concentration $(86.84 \pm 33.81$ vs. $121.16 \pm 42.57 \mathrm{mg} / \mathrm{dL})$. The $\mathrm{r}$-bST treatment reduced the total cholesterol and HDL levels $(82.46 \pm 19.25$ vs. $89.29 \pm 23.66$ and $155.95 \pm 19.67 \times 177.67 \pm 32.79 \mathrm{mg} / \mathrm{dL}$ for $\mathrm{T} 1$ and $\mathrm{T} 2$, respectively) in lactating goats. Concentrations of albumin, glucose, total proteins, $\beta$-hidroxybutirate and thyroxin as well as body weight and body condition score all remained unchanged comparing both treatments. It can be concluded that r-bST increased milk lactose content, reduced somatic cells count, and changed the profile of blood metabolites of Toggenburg goats.

Key Words: goat, lactation, metabolite, milk composition, thyroxin 


\section{Introdução}

A capacidade do hormônio do crescimento $(\mathrm{GH})$ de aumentar a produção de leite em ruminantes lactantes tem sido bem estabelecida. A maioria dos estudos sobre as propriedades galactopoiéticas do GH tem detalhado efeitos em vacas (Bauman, 1992; Burton et al., 1994) e respostas semelhantes em ovelhas e cabras, embora poucos tenham relatado alteração na produção de leite (Nielsen, 1988; Davis et al., 1989; Fernandez et al., 1995).

Os mecanismos envolvidos no efeito galactopoiético do GH podem ser classificados em três tipos: aumento na capacidade de síntese da glândula mamária (Nielsen, 1988) - ação mediada pela somatomedina mais específica, o IGF-1, pois o tecido mamário não possui receptores para a somatotropina (Prosser \& Mepham, 1989); alteração na glândula mamária, que promove a utilização de nutrientes e a mobilização de substratos que fornecem nutrientes essenciais para a síntese do leite (Soderholm et al., 1988); e aumento preferencial no fluxo sangüíneo para a glândula mamária (Mepham et al., 1984).

Em ovelhas, a r-bST é biologicamente ativa (Bauman, 1992), mas, em cabras, os estudos são limitados e poucos têm relatado seus efeitos sobre a composição do leite e dos metabólicos sangüíneos (Knight et al., 1990; Prosser et al., 1991; Disenhaus et al., 1995).

Objetivou-se estudar a influência da aplicação de somatotropina bovina recombinante (r-bST) sobre a produção e composição do leite, os metabólitos sangüíneos e a concentração hormonal de cabras Toggenburg em lactação.

\section{Material e Métodos}

O estudo foi conduzido na granja Água Limpa no período de maio a julho de 2003 , a $21^{\circ} 35^{\prime}$ de latitude sul e $43^{\circ} 15^{\prime}$ de longitude leste, altitude média de $435 \mathrm{~m}$, clima Cwa, segundo classificação de Köeppen (inverno seco e verão úmido) com temperatura média anual de $21^{\circ} \mathrm{C}$ e precipitação pluviométrica média anual de $1.581 \mathrm{~mm}^{3}$.

Foram utilizadas 24 cabras Toggenburg $(98,8 \pm 1,92$ dias de lactação), sendo 12 multíparas (M), com 49,1 $\pm 5,7 \mathrm{~kg}$ e escore da condição corporal $3,1 \pm 0,5$, segundo escala de 1 a 5 , em que $1=$ muito magra e $5=$ obesa, e 12 primíparas $(\mathrm{P})$, com 41,2 $\pm 5,6 \mathrm{~kg}$ e escore da condição corporal 3,7 $\pm 0,8$.

Os animais foram mantidos em confinamento, recebendo dieta formulada para suprir as exigências nutricionais de cabras no terço médio da lactação, segundo NRC (1981), e água ad libitum. O volumoso utilizado foi capim-elefante (Pennisetum purpureum Schum) picado e o concentrado foi constituído por milho, farelo de soja, farelo de girassol e mistura mineral. Consta na Tabela 1 a composição química do volumoso e na Tabela 2 , a composição percentual da dieta.

Os animais foram distribuídos em um delineamento inteiramente casualizado, em dois tratamentos: T1 $(6 \mathrm{M} \mathrm{e}$ $6 \mathrm{P})=$ as cabras pesavam $44,8 \pm 6,0 \mathrm{~kg}$, apresentavam escore de condição corporal de $3,3 \pm 0,8$ e receberam quatro injeções de 250 mg de r-bST (Sometribove ${ }^{1}$ ), via subcutânea,

Tabela 1- Composição química do capim-elefante (Pennisetum purpureum, Schum $)^{1}$

Tabela 1 - Chemical composition of elephantgrass (Pennisetum purpureum, Schum $)^{1}$

\begin{tabular}{lr}
\hline Componente & $\% \mathrm{MS}$ \\
Item & $D M \%$ \\
\hline Matéria seca (Dry matter) & 15,90 \\
Proteína bruta (Crude protein) & 8,00 \\
Extrato etéreo (Ether extract) & 1,00 \\
Fibra em detergente ácido (Acid detergent fiber) & 39,20 \\
Fibra em detergente neutro (Neutral detergent fiber) & 70,00 \\
Matéria mineral (Ash) & 10,80 \\
Cálcio (Calcium) & 0,40 \\
Fósforo (Phosphorus) & 0,20 \\
Magnésio (Magnesium) & 0,30 \\
Potássio (Potassium) & 2,80 \\
Sódio (Sodium) & 0,04 \\
\hline
\end{tabular}

${ }_{1}^{1}$ Análise realizada no Laboratório de Nutrição Animal do DZO/UFV.

${ }^{1}$ Analysis were done at Animal Nutrition Laboratory of DZO/UFV.

Tabela 2 - Composições percentual da dieta e química do concentrado ${ }^{1}$

Tabela 2 - Ingredient and chemical composition of the concentrade ${ }^{1}$

\begin{tabular}{lr}
\hline Ingrediente & $\% \mathrm{MS}$ \\
Ingredient & $D M \%$ \\
\hline Capim-elefante (Elephantgrass) & 48,86 \\
Milho moído (Ground corn) & 28,34 \\
Farelo de soja (Soybean meal) & 13,26 \\
Farelo de girassol (Sunflower meal) & 10,52 \\
Mistura mineral (Mineral mixture) & 0,02 \\
\hline Componentes (Components) \\
\hline Matéria seca (Dry matter) \\
Proteína bruta (Crude protein) \\
Fibra buta (Crude fiber) & 88,10 \\
Extrato etéreo (Ether extract) & 3,18 \\
Matéria mineral (Ash) & 1,18 \\
Cálcio (Calcium) & 4,99 \\
Fósforo total (Total phosphorus) & 0,91 \\
\hline
\end{tabular}

${ }_{1}^{1}$ Análise realizada no Laboratório de Nutrição Animal do DZO/UFV.

${ }^{1}$ Analysis were done at Animal Nutrition Laboratory of DZO/UFV.

\footnotetext{
${ }^{1}$ Lactotropin $(500 \mathrm{mg})$ - Elanco.

${ }^{2} \beta$-hidroxibutirato - Sigma Diagnostic - USA; Proteínas Totais, Albumina, Uréia - Doles Reagentes e Equipamentos para Laboratório Ltda; Colesterol Totais e HDL - Laborlab; Glicose - Bioclin (Quibasa Química Básica Ltda).
} 
na prega cutânea lateral da raiz da cauda, alternando os lados esquerdo e direito, a intervalos de 14 dias; T2 (6M e $6 \mathrm{P})=$ as cabras, pesavam $45,5 \pm 7,7 \mathrm{~kg}$, apresentavam escore de condição corporal de 3,5 $\pm 0,7$ e receberam injeções de solução salina (controle), no mesmo local e intervalo de aplicação. As aplicações de r-bST e solução salina foram na $1 \stackrel{\mathrm{a}}{ }, 3^{\mathrm{a}}, 5^{\mathrm{a}} \mathrm{e}$ e $7^{\mathrm{a}}$ semanas, sendo que a $1^{\mathrm{a}} \stackrel{\mathrm{a}}{\mathrm{s}}$ semana correspondeu ao início do período experimental. Durante o período experimental (nove semanas), o leite foi pesado diariamente nas duas ordenhas, realizadas às $7 \mathrm{e} 16 \mathrm{~h}$. As amostras de leite foram coletadas semanalmente, para análise de seus constituintes (extrato seco - ES, gordura, lactose e proteína) e do número de células somáticas (CCS), e enviadas para análises no Laboratório de Qualidade do Leite do Centro Nacional de Pesquisa de Gado de Leite (Embrapa-Gado de Leite). As pesagens dos animais e a avaliação da condição corporal foram realizadas a cada 30 dias.

O sangue foi coletado semanalmente, a partir da primeira aplicação da r-bST, após a ordenha e antes da aplicação da r-bST, por punção da veia jugular, em tubos de coleta a vácuo $(10 \mathrm{~mL})$, sem solução anticoagulante, para análise dos níveis de hormônio (tiroxina - T4) e metabólitos (albumina, ácidos graxos não-esterificados - AGNE, $\beta$-hidroxibutirato - BOHB, proteínas totais - $\mathrm{PT}$, colesterol total - CT e fração HDL). A coleta de sangue para determinação da concentração de glicose foi realizada em tubos de coleta a vácuo contendo solução anticoagulante de fluoreto de sódio (inibidor da glicólise). Vinte minutos após a coleta, as amostras foram centrifugadas a $1.000 \mathrm{x} \mathrm{G}$, por 15 minutos, para separação do soro ou plasma, acondicionadas em tubetes de plástico, identificadas e armazenadas a $-18^{\circ} \mathrm{C}$.

As análises dos metabólitos sangüíneos e da tiroxina foram realizadas utilizando-se kits comerciais ${ }^{2}$, no Laboratório de Reprodução Animal do DZO e no Laboratório de Proteínas do Bioagro - UFV, adotando-se as metodologias enzimática e de radioimunoensaio (RIA) em fase sólida, respectivamente, conforme recomendações dos fabricantes.

A análise estatística foi realizada pelo programa SAEG 8.0 (UFV, 1997), corrigindo-se a ordem de parto. Os dados foram analisados por análises de variâncias e as médias comparadas pelo teste Tukey, a 5\% de probabilidade.

\section{Resultados e Discussão}

Os resultados da produção e composição do leite são apresentados na Tabela 3 . A produção de leite não diferiu $(\mathrm{P}>0,05)$ entre os tratamentos, embora tenha ocorrido aumento de 8,0 a $28,6 \%$ na produção de leite das cabras tratadas com r-bST (Nielsen, 1988; Disenhaus et al., 1995;
Chadio et al., 2000). Neste estudo, não houve aumento na produção de leite, provavelmente em razão da utilização de dose diferente de r-bST e do estádio da lactação, visto que, Chadio et al. (2000) administraram $160 \mathrm{mg}$ de r-bST em cabras da raça Alpina na $8 \underline{a}$ semana de lactação e, neste estudo, foram aplicados $250 \mathrm{mg}$ na $14^{\mathrm{a}}$ semana de lactação, quando a resposta fisiológica provavelmente não seria a mesma.

Não houve efeito $(\mathrm{P}>0,05)$ dos tratamentos (Tabela 3$)$ sobre os teores de gordura, extrato seco e proteína do leite, como observado por Barbosa et al. (2002), em cabras da raça Alpina a partir dos 45 dias de lactação, e Baldi (1999) e Baldi et al. (2002), que não notaram alteração na porcentagem de gordura no leite de cabras Saanen tratadas com r-bST. Chadio et al. (2000) também não observaram efeito da bST sobre a porcentagem de proteína do leite em cabras da raça Alpina a partir da $8^{\mathrm{a}}$ semana de lactação. O efeito do $\mathrm{GH}$ sobre a proteína do leite não era esperado, pois a composição do leite pode variar com o status energético do animal. Oldenbroek \& Garssen (1992) não constataram mudança nas porcentagens de proteína e gordura do leite em vacas com balanço energético positivo.

Houve aumento nos teores de lactose $(\mathrm{P}<0,05)$ no leite dos animais tratados com r-bST (Tabela 3), como reportado por Stelwagen et al. (1993) e Chadio et al. (2000), provavelmente em decorrência do maior transporte de glicose para dentro das células mamárias, relacionado às propriedades diabetogênicas do GH (Hart et al., 1985).

A CCS, um índice de qualidade do leite (Paape \& Capuco, 1997), foi menor $(\mathrm{P}<0,05)$ no leite das cabras tratadas com r-bST (Tabela 3), confirmando os resultados decritos por Baldi et al. (2002). Knight (1998), citado por Baldi et al. (2002), reportou que a administração de somatotropina bovina reduz a CCS porque previne a perda de células secretoras e aumenta a produção de leite. Como neste trabalho não houve aumento da produção de leite, conclui-se que ocorreu menor perda de célula secretora nos animais tratados com r-bST.

O peso e o escore de condição corporal dos animais não foram influenciados pelo tratamento com r-bST $(\mathrm{P}>0,05$; Tabela 4). Esses resultados corroboram os achados de Chadio et al. (2002), que não observaram efeito do tratamento com r-bST sobre o peso dos animais, e de Barbosa et al. (2002), que também não verificaram efeito sobre o peso e o escore corporal dos animais.

A glicose, o $\beta$-hidroxibutirato (BOHB) e o AGNE são metabólitos sangüíneos indicados para avaliação do status energético do animal, sendo BOHB e AGNE relacionados à taxa de mobilização de reservas lipídicas. 
O perfil sérico de AGNE ( $\mathrm{mEq} / \mathrm{L}$ ) em cabras lactantes da raça Toggenburg, tratadas com r-bST, durante o período experimental, encontra-se na Figura 1. Houve diferença nas concentrações de AGNE na $4^{\mathrm{a}}$ e $6^{\mathrm{a}}$ semanas subseqüentes à administração da r-bST entre os animais dos tratamentos, indicando que o efeito do r-bST foi evidenciado apenas na semana seguinte à aplicação da $3^{\underline{a}}$ e $5^{\underline{a}}$ dose. A partir da $6^{\underline{a}}$ semana, não houve diferença entre os animais dos tratamentos $(\mathrm{P}>0,05)$. O aumento na concentração de $\operatorname{AGNE}(\mathrm{P}<0,05$; Tabela 5) em cabras tratadas com r-bST demonstra que houve mobilização de reservas corporais de lipídeos. Possivelmente, o AGNE foi utilizado pelos tecidos periféricos como alternativa energética em substituição à glicose e também para a síntese de ácidos graxos de cadeia curta do leite. Disenhaus et al. (1995) reportaram resultado semelhante quanto às concentrações de AGNE, ao verificarem que animais ruminantes em lactação se adaptam ao aumento da demanda de nutrientes para suprir o aumento da produção, sem comprometimento da saúde. Lanna et al. (1995) constataram que r-bST altera o metabolismo de lipídeos no tecido adiposo e observaram que vacas no terço médio da lactação e com balanço energético positivo apresentaram redução da síntese lipídica no tecido adiposo, indicando que o tratamento com r-bST promoveu aumento do substrato e dos triglicerídeos para viabilizar o aumento da síntese de leite. A administração de bST aumenta a secreção de ácidos graxos de cadeias curta e média no leite por litro e, conseqüentemente, a produção diária (Disenhaus et al., 1995).

Tabela 3 - Produções médias de leite, gordura, proteína, lactose e extrato seco e contagem de células somáticas (CCS) do leite de cabras da raça Toggenburg, tratadas com r-bST

Table 3 - $\quad$ Average yields of milk, fat, protein, lactose, dry extract and somatic cells number (SCC) of milk from Toggenburg breed goats treated with $r$-bST (mean \pm standard deviation)

\begin{tabular}{lccc}
\hline Itens & r-bST & $\begin{array}{c}\text { Controle } \\
\text { Control }\end{array}$ & CV (\%) \\
\hline $\begin{array}{l}\text { Produção (kg/semana) } \\
\text { Production (kg/week) }\end{array}$ & $9,00 \pm 3,0$ & $8,86 \pm 3,0$ & 34,04 \\
$\begin{array}{l}\text { Gordura (\%) } \\
\text { Fat (\%) }\end{array}$ & $4,44 \pm 0,8$ & $4,39 \pm 0,9$ & 18,80 \\
$\begin{array}{l}\text { Proteína (\%) } \\
\text { Protein (\%) }\end{array}$ & $3,30 \pm 0,4$ & $3,31 \pm 0,5$ & 13,68 \\
$\begin{array}{l}\text { Lactose (\%) } \\
\text { Lactose (\%) }\end{array}$ & $4,47 \pm 0,2^{\mathrm{a}}$ & $4,34 \pm 0,2^{\mathrm{b}}$ & 5,59 \\
$\begin{array}{l}\text { Extrato Seco (\%) } \\
\text { Dry extract (\%) }\end{array}$ & $13,23 \pm 1,1$ & $13,03 \pm 1,4$ & 9,49 \\
$\begin{array}{l}\text { CCS } \\
\left(\mathrm{x} 10^{3} \text { células/mL) }\right.\end{array}$ & $695,16 \pm 689,9^{\mathrm{a}}$ & $1.001,84 \pm 610,9^{\mathrm{b}}$ & 74,75 \\
$\begin{array}{l}\text { SSC } \\
\left(x 10^{3} \text { célls/mL) }\right.\end{array}$ & & & \\
\hline
\end{tabular}

Médias, na linha, seguida por letras distintas diferem entre si $(P<0,05)$ Means, in a row, followed by different letters differ $(P<0.05)$.
As concentrações séricas de BOHB nos animais não diferiram $(\mathrm{P}>0,05)$ entre os tratamentos (Tabela 5), corroborando os resultados obtidos por Chadio et al. (2000), que também não observaram efeito da administração de r-bST sobre os níveis deste metabólito. Quanto maior a mobilização de ácido graxo do tecido adiposo, maior a concentração de AGNE, cujo metabolismo hepático é dependente da concentração de AGNE e de glicose disponível. Quando o limite do metabolismo hepático é excedido, o AGNE é convertido em BOHB (Studer et al., 1993). Apesar do aumento na concentração de AGNE, não houve aumento nas concentrações de $\mathrm{BOHB}$, sugerindo que o limiar do metabolismo de AGNE não foi excedido.

Estudos indicam que o BOHB é utilizado pela glândula mamária para síntese de gordura do leite (Lean et al., 1992). Como não houve efeito da r-bST sobre as concentrações de BOHB, não ocorreu aumento no teor de gordura do leite (Tabela 3).

As concentrações plasmáticas de glicose não foram influenciadas $(\mathrm{P}>0,05)$ nos animais de ambos os tratamentos (Tabela 5). Ao contrário, Knapp et al. (1992) relataram que administração de r-bST aumentou a concentração de glicose na circulação sangüínea, pois promoveu a gliconeogênese a partir de precursores como aminoácidos e glicerol. Durante administração de r-bST, ocorre adaptação metabólica no turnover e na oxidação da glicose, conciliando o requerimento adicional da glicose para aumentar a síntese de lactose (González et al., 2000). Fernández et al. (1995) encontraram valores de 32,0 a $77,0 \mathrm{mg} / \mathrm{dL}$ em caprinos.

As concentrações séricas de proteínas totais (PT) não diferiram $(\mathrm{P}>0,05)$ entre os animais dos tratamentos (Tabela 5). $\mathrm{O}$ valor-referência encontrado para caprinos foi de 6,6 a 8,4 g/dL (González, 2000). Portanto, o tratamento com r-bST não alterou as concentrações de PT em cabras no terço médio da lactação.

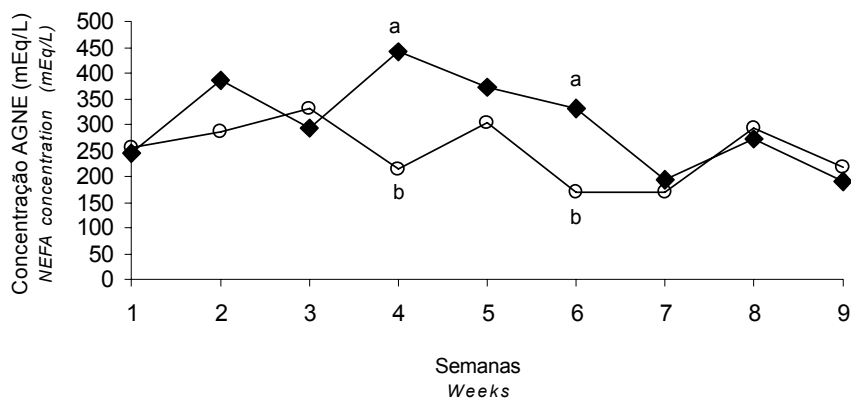

Figura 1 - Perfil sérico de ácidos graxos não-esterificados (AGNE) (mEq/L) em cabras da raça Toggenburg em lactação tratadas com r-bST $(\bullet)$, durante o período experimental.

Figure 1 - Profile of serum nonesterified fatty acid (NEFA) (mEq/L) in lactating Toggenburg goats, treated with $r-b S T(\diamond)$, during the experimental period.

a, b $P<0,05(P<0.05)$ 
Tabela 4 - Médias de peso e escore da condição corporal de cabras da raça Toggenburg em lactação tratadas com r-bST

Table 4 - Means of weight and body condition score in lactating Toggenburg goats treated with r-bST (mean \pm standard deviation)

\begin{tabular}{lcccc}
\hline & \multicolumn{2}{c}{$\begin{array}{c}\text { Peso }(\mathrm{kg}) \\
\text { Weight }(\mathrm{kg})\end{array}$} & \multicolumn{2}{c}{$\begin{array}{c}\text { Escore corporal } \\
\text { Body score }\end{array}$} \\
\cline { 2 - 4 } Semanas & r-bST & $\begin{array}{c}\text { Controle } \\
\text { Control }\end{array}$ & r-bST & $\begin{array}{c}\text { Controle } \\
\text { Control }\end{array}$ \\
\cline { 2 - 5 } & & $46,17 \pm 7,7$ & $3,52 \pm 0,8$ & $3,63 \pm 0,8$ \\
5 & $45,08 \pm 6,6$ & $46,33 \pm 7,5$ & $3,21 \pm 0,6$ & $3,33 \pm 0,6$ \\
9 & $45,98 \pm 6,0$ & $44,04 \pm 8,5$ & $3,27 \pm 0,8$ & $3,67 \pm 0,8$ \\
\hline
\end{tabular}

Médias seguida por letras distintas diferem entre si $(P<0,05)$.

Mean followed by different letters differ $(P<.05)$.

Tabela 5 - Concentrações médias de ácidos graxos nãoesterificado (AGNE), b-hidroxibutirato (BOHB), glicose, proteínas totais, uréia, albumina, colesterol total, colesterol HDL e tiroxina de cabras lactantes da raça Toggenburg tratadas com r-bST

Table 5 - Average concentrations of nonesterified fatty acids (NEFA), b-hidroxybutirate (BOHB), glucose, total proteins, urea, albumin, total cholesterol, HDL cholesterol and thyroxin of lactating Toggenburg goats, treated with $r$-bST

\begin{tabular}{lll}
\hline $\begin{array}{l}\text { Variável } \\
\text { Variable }\end{array}$ & \multicolumn{1}{c}{ r-bST } & \multicolumn{1}{c}{$\begin{array}{c}\text { Controle } \\
\text { Control }\end{array}$} \\
\hline $\begin{array}{l}\text { AGNE (mEq/L) } \\
\text { NEFA (mEq/L) }\end{array}$ & $309,67 \pm 169,62^{\mathrm{a}}$ & $247,34 \pm 126,38^{\mathrm{b}}$ \\
BOHB (mg/dL) & $0,542 \pm 1,72$ & $0,691 \pm 3,67$ \\
Glicose (mg/dL) & $74,30 \pm 15,85$ & $71,14 \pm 15,08$ \\
$\begin{array}{l}\text { Glucose }(\mathrm{mg} / \mathrm{dL}) \\
\text { Proteínas totais (g/dL) }\end{array}$ & $7,36 \pm 0,63$ & $7,50 \pm 0,60$ \\
$\begin{array}{l}\text { Total protein (g/dL) } \\
\text { Uréia (mg/dL) }\end{array}$ & $82,46 \pm 33,81^{\mathrm{a}}$ & $123,01 \pm 42,57^{\mathrm{b}}$ \\
$\begin{array}{l}\text { Urea (mg/dL) } \\
\text { Albumina (g/dL) }\end{array}$ & $2,84 \pm 0,38$ & $2,80 \pm 0,30$ \\
$\begin{array}{l}\text { Albumin (g/dL) } \\
\text { Colesterol total (mg/dL) }\end{array}$ & $82,46 \pm 19,25^{\mathrm{a}}$ & $89,29 \pm 23,66^{\mathrm{b}}$ \\
$\begin{array}{l}\text { Total cholesterol (mg/dL) } \\
\text { Colesterol HDL (mg/dL) }\end{array}$ & $155,95 \pm 19,67^{\mathrm{a}}$ & $177,67 \pm 32,79^{\mathrm{b}}$ \\
HDL cholesterol (mg/dL) & & \\
Tiroxina (mg/dL) & $4,53 \pm 1,47$ & $4,82 \pm 1,29$ \\
Thyroxin (mg/dL) & & \\
\hline
\end{tabular}

Médias, na linha, seguidas de letras distintas diferem entre si $(P<0,05)$. Means, in a row, followed by different letters differ $(P<0.05)$.

O teor de uréia foi menor nos animais tratados $(\mathrm{P}<0,05)$ (Tabela 5) e está relacionado à síntese protéica na glândula mamária, pois, para aumentar a proteína do leite, é necessário aminoácido ou nitrogênio não-protéico. Eisemann et al. (1989) evidenciaram o efeito da r-bST exógena sobre o metabolismo dos aminoácidos, uma vez que a somatotropina poupa aminoácidos do catabolismo, diminuindo a excreção de nitrogênio pela urina (Sechen et al., 1989). Assim, aumenta a utilização de aminoácidos com o aumento da síntese protéica na glândula mamária (Bauman et al., 1988) e, conseqüentemente, a concentração de uréia no plasma diminui com o tratamento com bST (Disenhaus et al., 1995). Sauvant et al. (1988) e Disenhaus et al. (1995) observaram redução na concentração de uréia plasmática e aumento nos teores de proteína do leite em cabras tratadas com r-bST. A somatotropina possui efeito de partição do nitrogênio para atender às exigências da glândula mamária. Entretanto, o mecanismo que fornece aminoácido para as células secretoras da glândula mamária não foi estabelecido, pois a porcentagem de proteína do leite das cabras tratadas com r-bST não diferiu daquela registrada no tratamento controle.

O valor da albumina sérica não diferiu $(\mathrm{P}>0,05)$ entre os tratamentos (Tabela 5). As concentrações encontradas coincidem com os valores de referência $(2,5 \mathrm{a} 4,1 \mathrm{~g} / \mathrm{dL})$ para metabólitos protéicos em caprinos (González, 2000). A albumina, além de várias funções, está relacionada à síntese de proteína do leite. A redução na concentração de albumina pode ser resultado da menor disponibilidade de aminoácidos para o fígado, priorizando a síntese do leite (Gregory \& Siqueira, 1983). Como não houve efeito da r-bST sobre a produção de leite dos animais tratados, as concentrações séricas de albumina não foram alteradas.

Os teores séricos de colesterol total (CT) e colesterol HDL foram menores $(\mathrm{P}<0,05)$ nos animais tratados com r-bST (Tabela 5). O colesterol está presente nas lipoproteínas HDL e LDL e seu teor plasmático pode variar de acordo com a produção leiteira. O CT é um indicador da habilidade de ruminantes em mobilizar os estoques de tecido adiposo para a síntese de leite (Kappel et al., 1984), pois grande proporção de triacilgliceróis transportados pelas lipoproteínas do sangue entra na glândula mamária. Portanto, os ácidos graxos utilizados para sintetizar os triacilgliceróis do leite provêm de duas fontes: lipídios do sangue e síntese de novo nas células epiteliais mamárias (Hurley, 2002). A ação da somatotropina é mediada principalmente pelas somatomedinas, fator de crescimento semelhante à insulina (IGF-1), sintetizado nos hepatócitos (Hadley, 1996), que, entre outras funções, aumenta a captação e absorção de lipoproteínas (Grummer \& Carroll, 1988), justificando a 
diminuição das concentrações séricas de CT e HDL dos animais que receberam tratamento com r-bST.

Tiroxina (T4)é o hormônio predominante da tireóide e tem pouca atividade biológica, enquanto o hormônio triiodotironina (T3) é mais ativo. O T4 é convertido em T3 pela enzima $5^{\prime}$-deiodinase $\left(5^{\prime} \mathrm{D}\right)$, em um processo conhecido como deiodinação enzimática. Capuco et al. (1989) verificaram relação positiva entre a atividade da 5'D na glândula mamária e a produção de leite de vacas tratadas com bST. O incremento na produção foi seguido por um aumento da atividade da 5'D no tecido mamário, apesar de sua atividade não ter sido alterada no fígado e nos rins. Segundo Burman et al. (1996), o GH tem efeito sobre a concentração sérica dos hormônios da tireóide, que têm importante papel sobre a produção de leite e estimulam a taxa metabólica em bovinos (Blum et al., 1983).

Não houve efeito $(\mathrm{P}>0,05)$ dos tratamentos sobre as concentrações séricas de tiroxina (T4) (Tabela 5), o que está de acordo com os resultados encontrados por McClean \& Laarveld (1991), que não verificaram efeito da administração de somatotropina sobre o eixo hipotalâmico-hipofisáriotireoideano e, conseqüentemente, sobre a concentração de T4 em vacas lactantes, em decorrência do estádio de lactação (terço médio da lactação). A concentração plasmática de T4 e a produção de leite se correlacionaram negativamente nos animais tratados com $r-b S T(r=-0,58 ; P<0,01$ versus $r=-0,40$; $\mathrm{P}<0,01$, nos animais controle).

\section{Conclusões}

A somatotropina bovina recombinante (r-bST) aumentou os teores de lactose e reduziu o número de células somáticas do leite de cabras. Entretanto, não influenciou a produção de leite e as porcentagens de gordura, proteína e extrato seco do leite e provocou alterações metabólicas.

\section{Agradecimento}

Ao CNPq, pela bolsa de estudos, à FAPEMIG, pelo financiamento a esta pesquisa e ao Departamento de Zootecnia da Universidade Federal de Viçosa.

\section{Literatura Citada}

BALDI, A. Manipulating of milk production and quality by use of somatotropina in dairy ruminants other than cows. Domestic Animal Endocrinology, v.17, p.131-137, 1999.

BALDI, A.; MODINA, S.; CHELI, F. et al. Bovine somatotropin administration to dairy goats in late lactation. Journal of Dairy Science, v.85, p.1093-1102, 2002.

BARBOSA, P.G.; GONÇALVES, H.C.; WECHSLER, F.S. et al. Uso da somatotropina bovina recombinante - r-bST como alternativa para produção de leite de cabra na entressafra. Revista
Brasileira de Zootecnia, v.31, n.5, p.2011-2023, 2002.

BAUMAN, D.E. Bovine somatotropina: review of emerging animal technology. Journal of Dairy Science, v.12, p.3432-3451, 1992.

BAUMAN, D.E.; EPPARO, P.J.; DE GUTER, M.J. Response of high-producting dairy cow to long - term treatment with pituitary somatotropin and recombinant somatotropin Journal of Dairy Science, v.68, n.6, p.1352-1362, 1988.

BLUM, J.W.; KUNZ, P.; LEUENBERGER, H. Thyroid hormones, blood plasma metabolites and haematological parameters in relationship to milk yield in dairy cows. Animal Production, v.36, p.93-104, 1983.

BURMAN, P.; HETTA, J.; WIDE, L. et al. Growth hormone treatment affects brain neurotransmitters and thyroxine. Clinical Endocrinology, v.44, p.319-324, 1996.

BURTON, J.L.; MCHIDE, B.N.; BLOCK, E. et al. A review of bovine growth hormone. Canadian Journal of Animal Science, v.74, n.2, p.167-201, 1994.

CAPUCO, A.V.; KEYS, J.E.; SMITH, J.J. Somatotrophin increases thyroxine-5'-monodeiodinase activity in lactating mammary tissue of the cow. Journal Endocrinology, v.121, p.205, 1989 .

ChADio, S.E.; MENEGATOS, J.; ZERVAS, G. et al. Pituitary responsiveness to gonadotropin- and thyrotropin-releasing hormones in goats treated with recombinant bovine somatotropin. Small Ruminant Research, v.46, p.149. $157,2002$.

CHADIO, S.E.; ZERVAS, G.; KIRIAUKOU, K. et al. Effects of recominant bovine somatotropin adminstration to lactating goats. Small Ruminant Research, v.35, p.263-269, 2000.

DAVIS, S.R.; GLUCKMAN, P.D.; HODGINSON, S.C. et al. Comparison of the effects of administration of recombinant bovine growth hormone or N-Mer-insulin-like growth factor-I to lactating goats. Journal Endocrinology, v.123, p.33-39, 1989.

DISENHAUS, C.; JAMMES, H.; HERVIEU, J. et al. Effects of recombinant bovine somatotropin on goat milk yield, composition and plasma metabolites. Small Ruminant Research, v.15, p.139-148, 1995 .

EISEMANN, J.H.; HAMMOND, A.C.; RUMSEY, T.S. et al. Nitrogen and protein metabolism and metabolites in plasma and urine of beef treated with somatotropin. Journal of Animal Science, v. 67, p. $105-115,1989$

FERNANDEZ, N.; RODRIGUEZ, M.; PERES, C. et al. Bovine somatotropin dose titration in lactating dairy ewes. Journal of Dairy Science, v.78, p.1073-1082, 1995.

GONZALEZ, F.H.D. Perfil metabólico em ruminantes: seu uso em nutrição e doenças nutricionais. Disponível em: $\underline{\text { www.ufrgs.com.br }}$ Acessado em: 08/02/2003), 2000.

GREGORY, R.M.; SIQUEIRA, A.J.S. Fertilidade de vacas de corte com diferentes níveis de albumina sérica em aleitamento permanente e interrompido. Revista Brasileira de Reprodução Animal, v.71, n.1, p.47-50, 1983.

GRUMMER, R.R.; BERTIS, S.J. Effect of prepartum propylene glycol administration on periparturient fatty liver in dairy cows. Journal of Dairy Science, v.76, p.2931-2939, 1993.

GRUMMER, R.R.; CARROLL, D.J. A review of lipoprotein cholesterol metabolism in importance to ovarian function. Journal of Animal Science, v.66, p.3160-3173, 1988.

HART, I.C.; CHADWICK, P.M.E.; JAMES, S. et al. Effect of intravenous bovine growth hormone or human pancreatic growth hormone-releasing factor on milk production and plasma hormones and metabolites in sheep. Journal Endocrinology, v.105, p.189-196, 1985.

HADLEY, M.E. Pituitary hormones. In: HADLEY, M.E. (Ed.) Endocrinology. 4. ed. New Jersey: Prentice Hall, 1996. 518p.

HURLEY, W.L. Lactation biology: milk fat synthesis. Department of Animal Sciences. College of Agricultural, Consumer and Environmental Sciences. Urbana: University of Illinois. Disponível em: http://www.classes.aces.uiuc.edu/ 
AnSci308/fatsynthesis.html. Acesso em: 17/02/2003.

KAPPEL, L.C.; INGRAHAM, R.H.; MORGAN, E.G. et al. Relationship between fertility and blood glucose and cholesterol concentration in Holstein cows. American Journal of Veterinary Research, v.45, n.12, p.2607-2612, 1984.

KNAPP, J.R.; FREETLY, H.C.; REIS. B.L. et al. Effects of somatotropin and substrates on patterns of liver metabolism in lactating dairy cattle. Journal of Dairy Science, v.75, p.1025-1035, 1992.

KNIGHT, C.H.; FOWLER, P.A.; WILDE, C.J. Galactopoietic and mamogenic effects of long-term treatment with bovine growth hormone and thrice daily milking in goats. Journal Endocrinology, v.127, p.129-138, 1990.

LANNA, D.P.D.; HOUSEKNECHET, K.L.; HARRIS, D.M. et al. Effect of somatotropina treatment on lipogeneses, lipolysis, and related cellular mechanisms in adipose tissue of lactating cows. Journal of Dairy Science, v.78, p.1703-1712, 1995.

LEAN, I.J.; BRUSS, M.L.; BALDWIN, R.L. et al. Bovine ketosis: A review: II. Biochemistry and prevention. The Veterinary Bulletin, v.62, n.1, p.1-14, 1992.

McCLEAN, C.; LAARVELD, B. Effect of somatotropin and protein supplement on thyroid function of dairy cattle. Canadian Journal of Animal Science, v.71, p.1053-1061, 1991.

MEPHAM, T.B.; LAWRENCE, S.E.; PETERS, A.R. et al. Effects of exogenous growth hormone on mammary function in lactating goats. Hormone and Metabolic Research, v.16, p.248-253, 1984.

NATIONAL RESEARCH COUNCIL - NRC. Nutrient requirements of goats. Washington, D.C.: National Academy of Science, 1981.

NIELSEN, M.O. Effect of recombinantly derived bovine somatotropin on mammary gland synthetic capacity in lactating goats. Journal of Animal Physiology and Animal Nutrition, v.59, p.263-272, 1988.

OLDENBROEK, J.K.; GARSSEN, J. Effects of treatment of dairy cows with recombinant bovine somatotropin over three or four lactations. Journal of Dairy Science, v.76, p.453-467, 1992.
PAAPE, M.; CAPUCO, A.V. Cellular defense mechanism in the udder and lactation of goats. Journal of Animal Science, v.75, p.556-565, 1997.

PROSSER, C.G.; MEPHAN, T.B. Mechanism of bovine somatotropin in increasing milk secretion in dairy ruminants. In: Use of somatotropin in livestock production. Elsevier Apllied Science, p.1-17, 1989.

PROSSER, C.G.; ROYLE, C.; FLEET, I.R. et al. The galactopoietic effect of bovine growth hormone in goats is associated with increased concentrations of insulin-like growth factor-I in milk and mammary tissue. Journal Endocrinology, v.128, p.457463, 1991.

SAUVANT, D.; KANN, G.; HERVIEU, J. et al. Effects of 1-29 GRF injections on milk production, voluntary feed intake, and nutritional status of lactating goats, Reproduction Nutrition Development, v.28 (supp1.1), p.179-180, 1988.

SECHEN, S.J.; BAUMAN, D.E.; TYRELL, H.F. et al. Effect of somatotropin on kinetics of nonesterified fatty acids and partition of energy, carbon and nitrogen in lactating dairy cows. Journal of Dairy Science, v.72, p.59-67, 1989.

SODERHOLM, C.G.; OTTERBY, D.E.; LINN, J.G. et al. Effects of recombinant bovine somatotropina on milk production, body composition and physiological parameters. Journal of Dairy Science, v.71, p.355-365, 1988 .

STELWAGEN, K.; GRIEVE, D.G.; WALTON, J.S. et al. Effect of prepartum bovine somatotropin in primigravid ewes on mammogenesis, milk production, and hormone concentrations. Journal of Dairy Science, v.76, p.992-1001, 1993.

STUDER,V.A.; GRUMER, R.R.; BERTIS, S.J. Effect of prepartum propylene glycol administration on periparturient fatty liver in dairy cows. Jornal of Dairy Science, v.76, p.2931-2939, 1993.

UNIVERSIDADE FEDERAL DE VIÇOSA - UFV. Sistema de análises estatísticas e genéticas 0 SAEG. Versão 7.1.Viçosa, MG: Editora UFV, 1997. 150p. (Manual do usuário)

Recebido: 07/10/04 Aprovado:08/08/05 